\title{
PENERAPAN BAHAN AJAR REALISTC MATHEMATICS EDUCATION (RME) TERHADAP KEMAMPUAN PEMAHAMAN KONSEP MATEMATIS SISWA
}

\author{
Laurinda Salsa Aldina Putri \\ Universitas Muhammadiyah Sukabumi \\ kakalaurinda20@gmail.com
}

\begin{abstract}
ABSTRAK
Tujuan penelitian ini adalah untuk mengkaji penggunaan bahan ajar matematika berbasis RME terhadap kemampuan konsep matematis siswa. Metode yang digunakan dalam penelitian ini adalah metode kualitatif dengan jenis penelitian studi kepustakaan. Dari hasil tersebut didapatkan kesimpulan bahwa pengunaan bahan ajar matematika berbasis RME sangat berpengaruh terhadap kemampuan pemahaman konsep matematis siswa, karena bahan ajar tersebut menjadikan 1) alat bantu siswa dalam memahami konsep 2) Siswa diberikan materi yang dikaitkan dengan kehidupan nyata yang akan menumbukan rasa semangat belajar.
\end{abstract}

Kata Kunci : realistic mathematic education, bahan ajar realistic mathematic education, kemampuan pemahaman konsep .

\section{PENDAHULUAN}

Matematika adalah mata pelajaran yang dipelajari di semua jenjang pendidikan (Karyanti \& Komarudin, 2017; Wahyuni et al., 2019). Matematika juga merupakan ilmu dasar yang memiliki peran dalam kehidupan, banyak sekali permasalahan yang ada dalam kehidupan kita ini dapat diselesaikan dengan matematika (E. Agustiana et al., 2018; Komarudin et al., 2014; Komarudin \& Permana, 2019). Walaupun banyak masyarakat yang mengatakan bahwa matematika ini sangatlah sulit untuk dipahami namun matematika banyak sekali digunakan dalam kehidupan kita.

Hudoyono (1988:3) mengatakan bahwa matematikan berkenaan dengan ide-ide atau konsep-konsep yang abstrak dan tersusun secara hierarki dan penalarannya dedukatif, disebutkan bahwa matematika adalah konsep yang hierarki yaitu suatu hal yang dimana hal-hal tersebut adalah sesuatu yang disusun, maka dalam matematika tidak boleh ada tahapan atau langkah-langkah kosep yang terlewati.

Belajar matematika hendaknya dipelajari dengan sistematis juga tersusun (N. Agustiana et al., 2019; Komarudin \& Thahir, 2019), lalu disampaikan dengan jelas, disesuaikan dengan perkembangan pengetahuan siswa, dengan demikian proses pembelajaran akan lebih efektif dan efisien.

Salah satu materi yang ada dalam matematika adalah Relasi dan Fungsi. Kompetensi yang harus dicapai pada materi tersebut yaitu siswa mampu memahami konsep Relasi dan Fungsi dan mengaplikasikannya dalam kehidupan sehari-hari. Namun pada kenyataanya tidaklah mudah untuk dicapai.

Kemampuan konsep matematika merupakan kemampuan yang utama yang diharapkan dapat tercapai dalam tujuan pembelajaran matematika (Komarudin et al., 2020; Wahyuni et al., 2019). Pemahaman menurut Purwanto (dalam Murizal 202:19) menyatakan bahwa pemahaman merupakan tingkat kemampuan yang mengharapkan siswa mampu memahami arti atau konsep, situasi, atau fakta yang diketahuinya. Lalu menurut Budiono (dalam Gusniwati, 2015:28) kosep matematika adalah segala sesuatu yang berwujud pengertian-pengertian, ciri khusus, hakikat dan isi materi matematika.

National Counsil of Teaching Mathematisc (NCTM) menyatakan bahwa kemampuan konsep matematika sangatlah penting yaitu : "Para peserta didik harus belajar matematika dengan pemahaman, secara aktif membangun pengetahuan baru dari pengalaman dan pengetahuan sebelumnya". Saat mempelajari matematika siswa harus memahami konsep matematika dahulu agar siswa dapat menyelesaikan soal-soal dan dapat mengaplikasikannya dalam kehidupan nyata ADDIN ZOTERO_ITEM CSL_CITATION \{ "citationID":"rrsh0ILg",,properties": \{ "formattedC itation":"(Akbar \& Komarudin, 2018; Puspita et al., 2020)","plainCitation":"(Akbar \& Komarudin, 2018; Puspita et al., 2020)","noteIndex":0\},"citationItems":[\{"id":403," 
uris":["http://zotero.org/users/4854509/items/RF7A NX85"],"uri":["http://zotero.org/users/4854509/ite ms/RF7ANX85"],"itemData": \{ "id":403,"type":"arti cle-journal","abstract":"This study aims to develop and test the feasibility of instructional videos of assisted social media Instagram as an alternative learning based on the feasibility of the assessment of media experts and materials experts. This research method is 7 stages from 10 stages of Borg and Gall model which have been modified by Sugiyono covering Potency and Problem, Collecting Data, Product Design, Design Validation, Design Revision, Product Trial and Product Revision. This research produces a medium of instructional video of math-aided social media of Instagram which has been declared valid and proper to be used as media of mathematics learning by 3 material experts get average score 88,8 (Very worthy) and 3 media expert with average score 93,55 (Very Eligible) with each maximum score of eligibility is 100 . So it can be concluded that the instructional media of instructional-assisted mathematics Instagram as a valid learning alternative and suitable for use as a medium of learning mathematics.","containertitle":"Desimal:

Jurnal

Matematika","DOI":"10.24042/djm.v1i2.2343","IS

SN":"2613-

9081","issue":"2","language":"en","page":"209-

215","source":"www.ejournal.radenintan.ac.id","titl e":"Pengembangan Video Pembelajaran Matematika Berbantuan Media Sosial Instagram sebagai Alternatif Pembelajaran","volume":"1","author":[ \{ "family":" Akbar","given":"Reza Rizki

Ali"\},\{"family":"Komarudin","given":"Komarudin "\}],"issued": \{ "date-

parts":[["2018",5,31]]\}\}\},\{"id":1360,"uris":["http:// zotero.org/users/4854509/items/PPZ7Z6DL"],"uri": ["http://zotero.org/users/4854509/items/PPZ7Z6DL "],"itemData":\{ "id":1360,"type":"article-

journal","container-title":"JPBI (Jurnal Pendidikan Biologi Indonesia)","issue":"2","note":"ISBN: 2527-6204","page":"347-354","title":"Analysis of problem-solving skills: Impact of guided inquiry learning model based on Islamic values","volume":"6","author":[\{ "family":"Puspita ","given":"Laila" \},\{ "family":"Komarudin","given": "K." \},\{"family":"Astriani","given":"Maya"\}],"issu ed": \{ "date-

parts":[["2020"]]\}\} \}],"schema":"https://github.com /citation-style-language/schema/raw/master/csl- citation.json" \} (Akbar \& Komarudin, 2018; Puspita et al., 2020). Maka dari itu pemahamanan konsep perlu ditanamkan kepada siswa sejak dini yaitu saaat duduk di bangku sekolah dasar. Siswa dituntut untuk mengerti tentang definisi, pengertian, cara memecahkan masalah maupun mengoperasikan matematika secara tepat. Karena hal itu akan memberikan bekal untuk siswa pada saat siswa menginjak jenjang pendidikan yang lebih tinggi.

Namun kemampuan pemahaman konsep yang rendah terlihat ketika siswa tidak dapat mengaplikasikan suatu konsep pada materi. Metode yang sering digunakan dalam proses pembelajaran adalah model pembelajaran kovensional, pemberian materi melalui buku paket membuat siswa malas untuk membaca dan mencatat, karena membaca mencatat materi membuat waktu proses pembelajaran menjadi sedikit dan menjadikan pembelajaran dikelas menjadi membosankan.

Aktivitas yang banyak dilakukan di dalam kelas yaitu pembelajaran yang menerapkan dimana guru yang meberikan materi terus menerus dan siswa hanya mendengarkan kemudian guru memberikan sebuah contoh soal dan siswa hanya memperhatikan saja. Hal ini yang membuat siswa menjadi malas untuk berpikir dan memahami konsep dari suatu materi, sehingga saat siswa mengerjan soal yag diberikan guru siswa tidak bisa menjawab dengan benar karena siswa tidak memahami konsep dari materi tersebut (Darma dan Firdaus, 2016).

Solusi yang dapat dilakukan untuk meningkatkan pemahaman konsep pada siswa adalah dengan mengembangkan bahan ajar yaitu Lembar Keja Siswa (LKS) dengan pembahasan yang mudah dimengerti siswa dengan menggunakan Bahasa sehari-hari yang akan memudahkan siswa untuk memahami materi. Oleh karena itu perlu adanya bahan ajar matematika berbasis Ralistic Mathematics Education (RME).

RME itu sendiri merupakan pendekatan yang menekankan pada konseptualisasi pengajaran dan memiliki kecenderungan siswa menjadi siswa aktif dalam proses belajar mengajar. Adapun lima karakteristik RME (Treffers, 1987; bakker, 2004) (1) Phenomenological Exploration (Eksplorasi Fenomenologi), untuk lebih memahami konsep matematika , kegiatan matematika harus ditempatkan dalam konteks yang konkret. (2) Using models and symbols for progressive mathemtization Menggunakan model dan simbol 
untuk ,matematikaisasi progresif, keragaman model dan simbol dan rancangan kegiatan ditujukan untuk membawa pemikiran siswa terhadap pengembangan pengerahuan mereka. (3) Using Student's own construction and productions ( menggunakan konstruksi dan produksi siswa) semua siswa dapat membuat strategi belajar mereka sendiri hal itu dapat menjadikan suatu solusi belajar mereka pada materi selanjutnya. (4) Interactivity (interaktivitas), para siswa tidak hanya belajar individu namun siswa juga belajar bersosialisasi.

(5) Interwinement (Keterkaitan), menggabungkan materi sehingga menjadikan pembelajaran matematika yang efektif.

Berdasarkan permasalahan diatas maka diterapkanlah pebelajaran matematika dengan meggunakan bahan ajar matematika berbasis Realistic Mathematics Education (RME) yang bertujuan untuk meningkatkan kemampuan pemahaman konsep matematis siswa. Tujuan dari penelitian ini adalah untuk mengetahui apakaha bahan ajar berbasis RME ini efektif dan efisien terhadap kemmapuan pemahaman konsep matematis.

\section{METODE PENELITIAN}

Metode yang digunakan dalam penelitian ini adalah metode penelitian kualitatif dengan jenis penelitian kepustakaan. Penelitian kepustakaan merupakan suatu jenis penelitian yang digunkaan

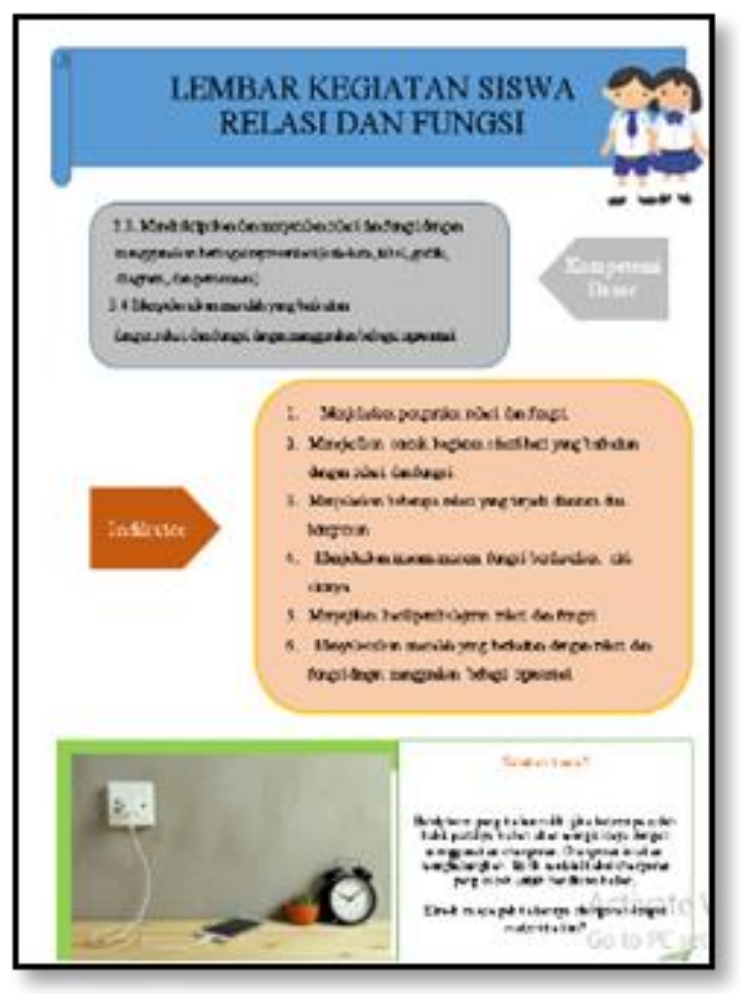

untuk pengumpulan informasi secara mendalam dengan berbagai macam cara yaitu dengan cara membaca buku, atau membaca hasil penelitian orang lain, dengan hal ini peneliti dapat mendapatkan jawaban dari masalah yang akan diteliti.

\section{HASIL DAN PEMBAHASAN}

Bahan pembelajaran adalah seperangkat bahan yang memuat materi atau isi pembelajaran yang "di desain" untuk mencapai tujuan pembelajaran (Sungkono dkk, 2003:1).fungsi dari penyusunan bahan ajar adalah (1) Sebagai pedoman bagi siswa yang akan mengarahkan semua aktivitasnya dalam proses pembelajaran, sekaligus merupakan substansi kompetensi yang seharusnya dipelajari/ dikuasainya (2) Pedoman bagi para guru yang akan mengarahkan semua aktivitasnya dala proses pembelajaran, sekaligus merupakan substansi kompetensi yangseharusnya diajarkan/ dilatihkan kepada siswanya. (3) Alat evaluasi/ penguasaan hasil pembelajaran.

Bahan ajar matematika berbasis Realistic Mathematics Education (RME) merupakan sekumpulan materi dan soal matematika yang didalamnya menjelaskan materi yang disangkut pautkan dengan kehidupan nyata. Dalam bahan ajar matematika berbasis Realistic Mathetmaitcs Education siswa akan diberikan materi dan soal yang menjuru ke dalam kehidupan nyata

\section{Gambar 1 Untuk Mendukung Pemahaman Awal Pada Konsep Matematis}

Dari gambar diatas dapat kita lihat bahwa bahan ajar matematika diatas berbasis Realistic Mathematics Education, siswa diperlihatkan sesuatu hal, benda yang ada dalam kehidupan kita yang sering kita jumpai dalam kehidupan kita dan dikaitkan dengan materi relasi. Dari gambar tersebut bisa terdapat sebuah gambar handphone dan charger handpone pastinya siswa sudah tidak akan asing lagi dengan benda tersebut. Siswa akan termotivasi dalam mempelajarai matematika karena materi yang dipelajari berkaitan dengan kehidupan nyata yang akan membuat siswa menjadi bersemangat dalam belajar.

Dalam bahan ajar ini siswa dapat memahami konsep dengan melakukan pengerjaan LKS tersebut. Ketika siswa diberikan LKS tersebut siswa diberi gambaran terlebih dahulu mengenai konsep materi yang akan di bahas, lalu siswa akan 
mengerjakan tugas yang ada pada LKS yang telah diberikan dengan berkelompok.
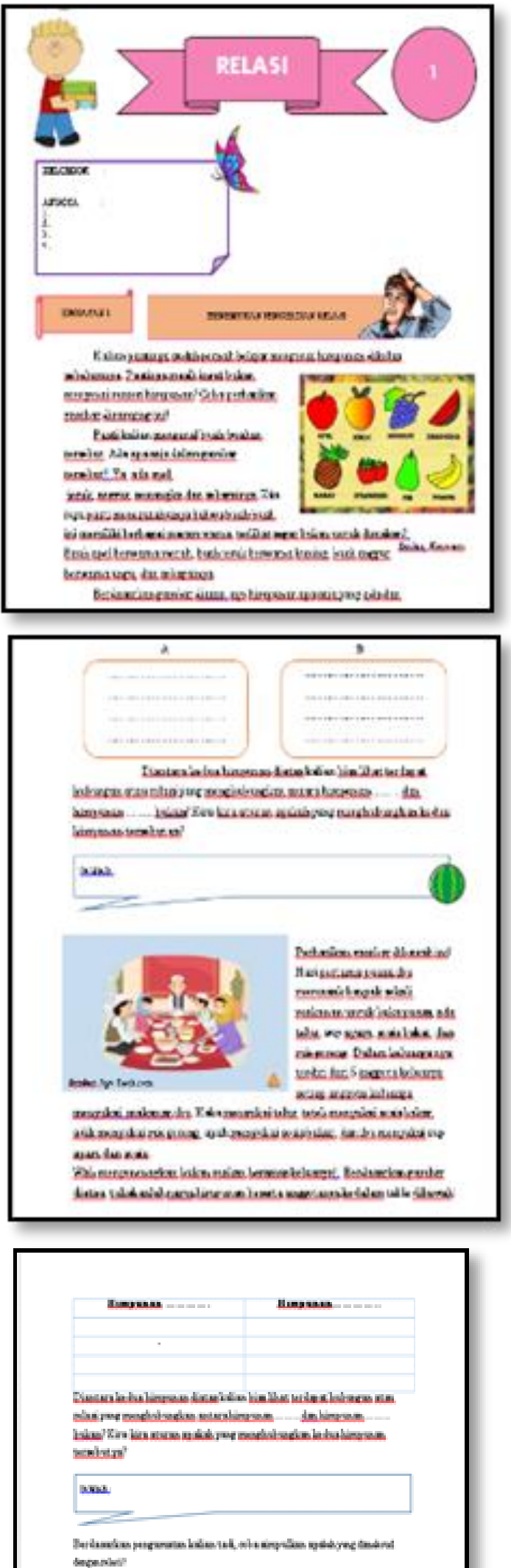

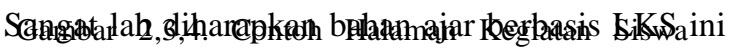
diptukmeMnglihatkaRepahnahamankosesep \$pswganlan senrmagala

\section{KESIMPULAN}

Bedasarkan hasil kajian tersebut maka dapat disimpulkan bahwa penerapan bahan ajar matematika berbasis Realistic Mathematics Education dangat diharapkan dapat meningkatkan kemampuan pemahaman konsep matematis siswa, karena :

1. Bahan ajar tersebut dijadikan alat bantu siswa dalam memahami konsep

2. Siswa diberikan materi yang dikaitkan dengan kehidupan nyata

\section{DAFTAR PUSTAKA}

Hernawan, Asep Herry,dkk.2012. "Pengembangan Bahan Ajar". (hlm. 1-13).

Herawati, Oktiana Dwi Putra,dkk.2010.” Pengaruh Pembelajaran Problem Posing Terhadap Kemampuan Pemahaman Konsep Matematika Siswa Kelas XI Ipa SMA Negeri 6 Palembang”. Jural Pendididkan Matematika Volume 4 No 1. Dosen Jurusan Magister Pendidikan Matematika PPs Unsri.

Imswatama, Aritsya. 2020. "Penerapan Bahan Ajar Matematika Berbasis Etnomatematika Terhadap Kemampuan Pemecahan Masalah Matematis Siswa". Universita Muhammadiyah Sukabumi.

Jati, Eko Pramono. 2014." Pengembangan Perangkat Pembelajaran Pada Materi Relasi Dan Fungsi Untuk Siswa Kelas VIII Dengan Pendekatan Penemuan Terbimbing". Program Studi Pendidikan Matematika Univeristas Negeri Yogyakarta.

Agustiana, E., Putra, F. G., \& Farida, F. (2018). Penerapan model pembelajaran Auditory, Intellectually, Repetition (AIR) dengan pendekatan lesson study terhadap kemampuan pemecahan masalah matematis peserta didik. Desimal: Jurnal Matematika, 1(1), 1-6. 
Agustiana, N., Supriadi, N., \& Komarudin, K. (2019). Meningkatkan Kemampuan Penalaran Matematis dengan Penerapan Pendekatan Bridging Analogy Ditinjau dari Self-Efficacy. Inovasi Pembangunan: Jurnal Kelitbangan, 7(1), 61-61.

Karyanti, K., \& Komarudin, K. (2017). Pengaruh Model Pembelajaran Kumon Terhadap Pemahaman Matematis Ditinjau Dari Gaya Kognitif Peserta Didik Pada Mata Pelajaran Matematika Kelas VIII SMP Negeri Satu Atap 4 Pesawaran. Prosiding Seminar Nasional Matematika Dan Pendidikan Matematika, 1, 89-94.

Komarudin, K., \& Permana, P. T. (2019). LKPD Berbasis Scientific Approach Terhadap Kemampuan Pemecahan Masalah Matematis Peserta Didik Sekolah Dasar. TERAMPIL: Jurnal Pendidikan Dan Pembelajaran Dasar, 6(1), 79-91. https://doi.org/10.24042/terampil.v6i1.4385

Komarudin, K., Puspita, L., Suherman, S., \& Fauziyyah, I. (2020). Analisis Pemahaman Konsep Matematis Peserta Didik Sekolah Dasar: Dampak Model Project Based Learning Model. DIDAKTIKA TAUHIDI: Jurnal Pendidikan Guru Sekolah Dasar, 7(1), 43-53.

Komarudin, K., Sujadi, I., \& Kusmayadi, T. A. (2014). Proses Berpikir Kreatif Siswa SMP
Dalam Pengajuan Masalah Matematikaditinjau Dari Gaya Kognitif Siswa (Studi Kasus Pada Siswa Kelas Viii-h SMP Negeri 1 Sukoharjo Tahun Pelajaran 2012/2013). Jurnal Pembelajaran Matematika, 2(1).

Komarudin, K., \& Thahir, A. (2019). Bahan Ajar Berbasis Mathematical Comic: Dampak Terhadap Peningkatan Pemahaman Matematis Peserta Didik. Jurnal Pendidikan Matematika RAFA, 5(2), 98-110.

Wahyuni, T., Komarudin, K., \& Anggoro, B. S. (2019). Pemahaman Konsep Matematis Melalui Model WEE Dengan Strategi QSH Ditinjau Dari Self Regulation. AKSIOMA: Jurnal Program Studi Pendidikan Matematika, 8(1), 65-72.

Ningsing, Fitri Indrayati. 2018. “Analisis Pemahaman Siswa SMP Dalam Menyelesaikan Masalah Matematika Ditinjau Dari Kecerdasan Emosional".Program Studi Pendidikan Matematika Universitas Islam Majapahit.

Ningsih, Yunika Lestaria. 2016. " Kemampuan Pemahaman Konsep Matematika Mahasiswa Melalui Penerapan Lembar AKtivitas Mahasiswa (LAM) Berbasis Teori APOS Pada Materi turunan". Edumatica Volume 06 Nomor 01(hlm.1-8). Program Studi Pendidikan Matematika Universitas PGRI Palembang. 